\title{
Sec12p requires Rer1p for sorting to coatomer (COPI)-coated vesicles and
} \section{retrieval to the ER}

\author{
Johannes Boehm¹, François Letourneur ${ }^{2, \star}$, Wolfgang Ballensiefen ${ }^{1}$, Dmitri Ossipov ${ }^{1}$, Corinne Démollière ${ }^{2}$ \\ and Hans Dieter Schmitt ${ }^{1, \dagger}$
}

1Department of Molecular Genetics, Max-Planck-Institute for Biophysical Chemistry, PO Box 2841, D-37018 Göttingen, Germany ${ }^{2}$ Basel Institute for Immunology, Grenzacherstrasse 487, $\mathrm{CH}-4005$ Switzerland

*Present address: Institut de Biologie et Chimie des Proteines IBCP, UPR412 CNRS 7, Passage du Vercors F-69367 LYON Cedex 07 France

†Author for correspondence (e-mail: hschmit@gwdg.de)

\section{SUMMARY}

In Saccharomyces cerevisiae cells lacking the Rer1 protein (Rer1p), the type II transmembrane protein Sec12p fails to be retained in the ER. The transmembrane domain of Sec12p is sufficient to confer Rer1p-dependent ER retention to other membrane proteins. In rer1 mutants a large part of the Sec12-derived proteins can escape to the late Golgi. In contrast, rer3 mutants accumulate Sec12derived hybrid proteins carrying early Golgi modifications. We found that rer3 mutants harbour unique alleles of the aCOP-encoding RET1 gene. ret1 mutants, along with other coatomer mutants, fail to retrieve KKXX-tagged type I transmembrane proteins from the Golgi back to the ER. Surprisingly rer3-11(=ret1-12) mutants do not affect this kind of ER recycling. Pulse-chase experiments using these mutants show that $\alpha C O P$ and Rer1p function together in a very early Golgi compartment to initiate the recycling of Sec12p-derived hybrid proteins. Rer1p protein may be directly involved in the retrieval process since it also recycles between the early Golgi and ER in a coatomer (COPI)-dependent manner. Rer1p may act as an adapter coupling the recycling of non-KKXX transmembrane proteins like Sec12p to the coatomer (COPI)-mediated backward traffic.

Key words: Coatomer, Endoplasmic reticulum, Recycling/RER1/SEC12

\section{INTRODUCTION}

The endoplasmic reticulum (ER) is the site of protein translocation and quality control while in the Golgi complex proteins coming from the ER are sorted to their different cellular destinations (Helenius, 1994; Palade, 1975). During the passage through these organelles proteins are processed in a highly ordered fashion which has been conserved throughout the evolution of eukaryotic cells (Hirschberg and Snider, 1987). To work properly, permanent residents of the ER and the Golgi must continuously be singled out from the massive, on-going traffic within and between these and later organelles. It is widely accepted that the transport between the compartments is mediated by vesicles (Rothman and Orci, 1992). The budding of different types of vesicles requires the assembly of distinct coats. Non-clathrin-coated vesicles, the COPI vesicles, carry the coatomer complex consisting of seven subunits $(\alpha, \beta$ , $\beta-, \gamma, \delta, \varepsilon$, and $\left.\zeta_{5} \mathrm{COP}\right)$. COPI vesicles have been proposed to mediate intra-Golgi transport as well as ER-to-Golgi transport (Rothman and Orci, 1992; Pepperkok et al., 1993; Duden et al., 1994). A second type of coat, COPII, was first identified in yeast. It is composed of the Sec23p-Sec24p and Sec13pSec31p complexes, the small GTPase Sar1p and Sec16p (Barlowe et al., 1994; Espenshade et al., 1995). Although both types of vesicles, COPI and COPII, bud from the nuclear envelope of yeast at least in vitro, COPII coated vesicles are mainly involved in the transport of cargo molecules from ER to Golgi (Bednarek et al., 1995).

Protein transport is not unidirectional (Pelham, 1988; Lewis and Pelham, 1996). Since vesicles mediate this transport, sorting can occur in two distinct ways: specific barriers may prevent proteins and lipids from entering sites of vesicle formation and thus from leaving a compartment. This mechanism represents true retention. Alternatively, recycling systems can withdraw ER or Golgi-resident proteins from the so-called bulk flow and retrieve these proteins to earlier compartments. Recycling proteins encounter modifying enzymes which are characteristic for the compartments they are passing through (Pelham, 1988; Jackson et al., 1993). Both mechanisms, retention and retrieval, are not exclusive and can function either in parallel or in combination.

Specific signals required for ER retention are conserved among eukaryotes. Soluble ER proteins carry a C-terminal sequence motif, KDEL in mammalian cells and HDEL in yeast (Pelham et al., 1988). Another C-terminal motif, the dilysine or KKXX motif of type I transmembrane proteins, is required for ER retention in both mammalian cells and yeast (Jackson et al., 1990; Nilsson et al., 1989; Gaynor et al., 1994; Townsley and Pelham, 1994). A double-arginine motif has been identified as the retention signal for a type II transmembrane protein (Schutze et al., 1994).

The factors mediating retention are also conserved through- 
out evolution. The $\mathrm{K}(\mathrm{H}) \mathrm{DEL}$ signal carried by soluble ER proteins including also a few type II transmembrane proteins is recognized by the Erd2 receptor in yeast and mammals, respectively (Semenza et al., 1990; Lewis and Pelham, 1990). Coatomer from mammalian cells and yeast binds to the KKXX motif carried by ER-resident type I transmembrane proteins (Cosson and Letourneur, 1994). In fact, most mutations causing a defect in the retention of KKXX-tagged membrane proteins lie in genes encoding subunits of the coatomer. Mutations affecting KKXX-recycling were found in RET1, SEC21, SEC27, RET2 and RET3 genes encoding $\alpha \mathrm{COP}, \gamma \mathrm{COP}$, $\beta$-COP, §COP and $\zeta$ COP, respectively (Letourneur et al., 1994; Duden et al., 1994; Cosson et al., 1996). Coatomer from ret1 and $\sec 27$ mutants is unable to bind dilysine motifs in vitro. Very recently it was found that in addition to the COP proteins two transmembrane proteins, Ufe1p and Sec20p, are also required for the recycling of both KKXX-tagged proteins and the HDEL-receptor (Lewis and Pelham, 1996; Cosson et al., 1997).

A third retention system in yeast may be specific for type II transmembrane proteins. The ER retention mutants rerl, rer2 and rer 3 mutants were isolated by using Sec12p-derived hybrid proteins (Nishikawa and Nakano, 1993; Boehm et al., 1994). Interestingly, Rer1p-ependent retention can be transferred to other type II membrane proteins simply by replacing their own transmembrane domain (TMD) with that of the Sec12 protein (Boehm et al., 1994; Sato et al., 1996). RERl encodes a protein which itself may contain four TMDs (Boehm et al., 1994; Sato et al., 1995).

rerl and rer3 mutants show no secretion of the HDELtagged $\mathrm{BiP} / \mathrm{Kar} 2$ protein, suggesting that these mutants are not deficient in the recycling of soluble ER proteins from the Golgi to the ER. Therefore, rerl and rer3 mutants are different from the erd mutants which were identified by Pelham and coworkers (Hardwick et al., 1990). Some functional overlap may, however, exist between rer mutants and the coatomer (COPI)-dependent retention of type I proteins. Here we show that rer3 defects represent unique alleles of RET1 suggesting that coatomer is required to $\mathrm{Sec} 12 \mathrm{p}$ recycling to the ER. In addition, we present evidence that Rer1p may act as an intermediary between Sec12p and coatomer.

\section{MATERIALS AND METHODS}

\section{Genetic techniques}

Standard techniques were used for mating of haploid strains, complementation analysis, sporulation and the analysis of tetrads (Sherman et al., 1986). The assays to detect retention defects using either Sec12- $\propto f$-invertase, Ste2-Wbp1p and invertase-Wbp1 hybrid proteins were described previously (Boehm et al., 1994; Letourneur et al., 1994; Gaynor et al., 1994).

\section{Strains and plasmids}

The yeast strains used are listed in Table 1. A schematic representation of the hybrid proteins used in this study is given in Fig. 1. The plasmids used for expressing SEC12-SUC2, STE2-WBP1 and SUC2-WBP1 hybrid genes were described previously (Boehm et al., 1994; Letourneur et al., 1994; Gaynor et al., 1994). In some experiments transient expression of SEC12-SUC2 hybrids was achieved by employing GAL1 regulated copies of the hybrid genes. These chimeras were expressed from single copy vectors (pGSEC12WT and pGSEC12 KR; URA3, CEN4-ARS1). These vectors were obtained by replacing the CYC1-SEC12 region of the pCSEC12 vectors (Boehm et al., 1994) by a corresponding GAL1-SEC12-containing fragment derived from pCEY6 (d'Enfert et al., 1991).

To place SEC22 chimeras under the control of the $C Y C 1$ promoter a $B g l I I$ site was created at the start codon of $S E C 22$ by PCR. The PCR product carried an AfIII, a $C l a \mathrm{I}$ and a BamHI site at the $3^{\prime}$-end of SEC22. These sites replace the TMD-encoding part of SEC22. This made it possible to insert pairs of annealed oligonucleotides encoding different TMDs as described previously (Boehm et al., 1994). The PCR product was first subcloned into pBluescript KS(+) (Stratagene, San Diego) for sequencing and further subcloning. A $1.1 \mathrm{~kb}$ EcoRIBam HI fragment was excised from vector pSCCZ-100 (a gift from W. Kibbe) and inserted into this pBluescript clone. Thus the SEC22 sequence was fused to codon 3 of a CYC1-lacZ hybrid gene. A $1.6 \mathrm{~kb}$ EcoRI-BamHI fragment carrying this CYC1-SEC22 fusion gene was used to replace the $C Y C 1-S E C 12$ hybrid gene in pCSEC12 ${ }^{\mathrm{KR}}$ to give vector pCSEC $22^{\mathrm{KR}}$. Annealed oligonucleotides fitting into pCSEC $22^{\mathrm{KR}}$ cleaved with $A f I \mathrm{II}$ and $\mathrm{ClaI}$ were inserted to fuse different TMD-encoding segments to the SEC22 sequences.

Table 1. Strains used in this study

\begin{tabular}{|c|c|c|}
\hline Yeast strain & Genotype & Source \\
\hline PS42-1A & MATa ura3 leu 2 his 3 trp1 lys 2 pep $4: \because H I S 3$ suc2- $\$$ & Boehm et al., 1994 \\
\hline R1R3-7A & MATa ret1-12(=rer3-11) ura3 leu2 his3 trp1 lys2 ade2 pep4::HIS3 suc2- $\Delta$ & This work \\
\hline R1R3-8B & MATa rer1::TRP1 ura3 leu2 his3 trp1 lys 2 ade2 pep $4:: H I S 3$ suc2- $\$$ & This work \\
\hline R1R3-10A & MATa ret1-12(=rer3-11) rer1::TRP1 ura3 leu2 his3 trp1 lys2 ade2 pep4::HIS3 suc2- $\triangle$ & This work \\
\hline RT1P4-4B & MATa ret1-1 ura3 leu2 his3 pep $4:: H I S 3$ suc2- $\triangle$ & This work \\
\hline SC21P4-7D & MATosec21-2 ura3 leu2 his3 trp1 lys 2 pep4::HIS3 suc2- $\$$ & This work \\
\hline SC27P4-2D & MATosec 27-1 ura3 leu2 his3 pep4::HIS3 suc2- $\Delta$ & This work \\
\hline JBD2-2A & MATa ura 3 leu 2 his 3 trp 1 lys 2 ade 2 ade 8 suc $2-\Delta$ & Boehm et al., 1994 \\
\hline $\mathrm{C} 21.27-2 \mathrm{D}$ & MATa ret1-27(=rer3-27) ura3 leu2 his3 trp1 ade8 suc 249 & Boehm et al., 1994 \\
\hline R3P4-10D & MATa ret1-12(=rer3-11) ura3 leu2 his3 lys2 ade2 suc2- $\Delta$ & Boehm et al., 1994 \\
\hline EGY101 & MATa ret1-1 ura3 leu2 his3 lys2 trp1 suc $2-\Delta$ & Letourneur et al., 1994 \\
\hline FLY35 & MATa ret1-27(=rer3-27) ura3 leu2 his3 trp1 ade8 suc2- $\$$ ste $2:: L E U 2$ STE2-WBP1::URA3 & This work \\
\hline FLY37 & MATa rer $1-25$ ura3 leu 2 his 3 trp 1 lys 2 ade 2 ade 8 suc $2-\triangle$ ste $2: \because L E U 2$ STE2-WBP1::URA3 & This work \\
\hline FLY85 & MATa ret1-12(=rer3-11) ura3 leu2 his3 lys 2 suc2- $\triangle$ ste $2:: L E U 2$ STE2-WBP1::URA3 & This work \\
\hline FLY62 & MATa ura3 leu2 his3 trp1 lys 2 ade 2 ade8 suc2-\$ ste $2:: L E U 2$ STE2-WBP1::URA3 & This work \\
\hline RH3048 & MATa sec12-4 ura3 leu2 his4 lys2 myc-EMP47::LEU2 & S. Schröder, Basel \\
\hline SC12R3 & MATosec12-4 ret1-12(=rer3-11) ura3 leu2 his4 lys 2 myc-EMP47::LEU2 & This work \\
\hline SC16d & MATda sec16-1 ura3 leu2 (heterozygous: his $4 /+$ lys $2 /+$ ade $2 /+$ ade $8 /+$ ) & This work \\
\hline SC16R3d & MATda sec16-1 ret1-12(=rer3-11) ura3 leu 2 his3 lys 2 (heterozygous:ade $2 /+$ trp $1 /+$ ) & This work \\
\hline SC1621a & MATda sec16-1 sec21-1 ura3 leu2 lys 2 trp1 (heterozygous:ade $2 /+$ ) & This work \\
\hline SC1627a & MATda sec16-1 sec27-1 ura3 leu2 lys 2 ade 8 ade 2 (heterozygous:his $3 /+$ trp $1 /+$ ) & This work \\
\hline
\end{tabular}


The $S U C 2$ sequences in pCSEC $22^{\mathrm{KR}}$ (URA3, CEN4-ARS1, CYC1$S E C 22-\alpha f-S U C 2$ ) were replaced by the last of four repeats encoding the afactor peptide as well as $310 \mathrm{bp} \mathrm{3'}$ of the stop codon of the MFd gene (Kurjan and Hershkovitz, 1982). A 1.7 kb EcoRI fragment containing the Mfo gene was subcloned into pBluescript KS(+). From this vector a $0.35 \mathrm{~kb} H i n d I I I-P v u I I$ fragment was excised and subcloned into HindIII and $P v u \mathrm{II}$ cleaved pCSEC $22^{\mathrm{KR}}$. The resulting plasmid was named pCCSEC22- $\alpha(U R A 3$, CEN4-ARS1, CYC1SEC22- $\alpha f-S U C 2)$.

The following plasmids were used to express epitope-tagged

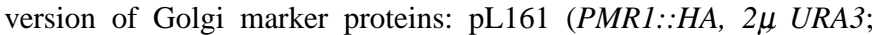
Antebi and Fink, 1992), SN218 (KEX2::HA, CEN6-ARSH1, URA3; Nothwehr et al., 1995), and pJOCH1 (TPI-OCH1::c-myc, $2 \mu$ URA3; a gift from M. Lewis, Cambridge).

To obtain isogenic pairs of mutant and wild-type strains pBLys-ret1 (Letourneur et al., 1994) was linearized with SalI. This cleavage should facilitate the integration of this vector at the RET1 locus. ret1 lys 2 mutants were transformed to $\mathrm{Lys}^{+}$. After the transformation the ret phenotypes were determined by back crossing to suitable tester strains. Alternatively, strains were transformed with a CEN-based vector carrying the RETl gene. To obtain such a vector a $5 \mathrm{~kb} \mathrm{SacI-}$ SalI fragment from pBLys-ret1 containing the RET1 gene was subcloned into vector pRS314 (TRP1, CEN6-ARSH1; Sikorski and Hieter, 1989).

\section{Antibodies}

Antibodies were raised against a peptide representing the 27 last residues of the Rer1 protein. An additional cysteine residue was introduced for efficient coupling of this peptide to the maleimide activated $\mathrm{KLH}$ protein (Pierce). For affinity purification this peptide was coupled to CNBr-activated Sepharose 4B (Pharmacia). This antibody as well as the following polyclonal or monoclonal antibodies was used for immunoblot analysis, immunoprecipitation and immunofluorescence experiments: anti-invertase and anti- $\alpha-6$ mannose antibodies (Boehm et al., 1994), anti-Sec22p antibodies (Ossig et al., 1991) the monoclonal antibody Y-27B1 directed against the C-terminal part of Ypt1p (Haubruck et al., 1987); a serum against BiP/Kar2p (M. Benli and D. Gallwitz, Göttingen); the c-myc specific monoclonal antibody 9E10 was obtained from Cambridge Research Biochemicals (Northwich); the HA-specific monoclonal antibody 12CA5 was from Boehringer (Mannheim). Cy3-conjugated anti-mouse IgG and FITCconjugated anti-rabbit IgG from goat (Dianova, Hamburg) were used as secondary antibodies in indirect immunofluorescence experiments. Peroxidase-conjugated anti-rabbit or anti-mouse IgG from donkey were obtained from Amersham-Buchler (Braunschweig).

\section{Indirect immunofluorescence}

Immunofluorescence was performed as described by Schröder et al. (1995). Cells were grown overnight to reach $A_{600} 1-1.5$. An equivalent of $10 A_{600}$ of cells was collected per each of two incubation temperatures. After adding $10 \mathrm{ml}$ of fresh medium containing $20 \mathrm{\mu g} / \mathrm{ml}$ of cycloheximide, cells were transferred to $25^{\circ} \mathrm{C}$ and $35^{\circ} \mathrm{C}$ water incubators for 1 hour. Then cells were pre-fixed by adding $1.3 \mathrm{ml}$ of $37 \%$ formaldehyde over one hour at room temperature and were resuspended in $1 \mathrm{ml}$ paraformaldehyde solution (3.5\% paraformaldehyde in PBS/10\% sorbitol). After 2 hours cells were washed once in PBS/10\% sorbitol, resuspended in $1 \mathrm{ml}$ of this solution. To remove cell walls samples were treated with lyticase $(30 \mu$ of $10 \mu \mathrm{g} / \mathrm{ml}$ solution) in the presence of 2-mercaptoethanol $(5 \mu / \mathrm{ml})$ for 1 hour. Sphaeroplasts were collected, washed 4 times in PBS/10\% sorbitol and resuspended in $400 \mu$ of PBS/10\% sorbitol, then $15 \mu$ of this suspension were applied to each slide well which was covered before by a poly-lysine solution (Sigma) to allow cell attachment. After 10 minutes the suspension was removed and $15 \mu$ of blocking solution (PBS/10\% sorbitol, 1\% Triton X-100, 1\% milk powder) were added for 10 minutes. Incubation with the first antibody was carried out overnight at $4{ }^{\circ} \mathrm{C}$ at appropriate dilutions in blocking solution.
Secondary antibodies (Cy3-conjugated $\mathrm{F}(\mathrm{ab})^{\prime}$ fragment of goat antirabbit IgG and anti-mouse IgG; Sigma) were added after 5 times washing of wells with PBS/10\% sorbitol solution. The wells were then washed 7 times, stained with DAPI and washed twice again in PBS/10\% sorbitol. About $200 \mu$ of embedding medium was applied on a slide that was then covered by a coverslip.

\section{Western blotting and immunoprecipitation}

Western blotting analysis and immunoprecipitation were performed as described by Boehm et al. (1994). Immunoprecipitations using antiSec22 antibodies were performed in the presence of a surplus of extract from a $\Delta e c 22$ strain (Ossig et al., 1991).

\section{RESULTS}

\section{rer3 mutants are defective in the retention of KKXX- tagged proteins}

To examine whether rer mutants alter ER retention of type I transmembrane proteins carrying the KKXX retrieval signal, we performed the Ste2-Wbp1-dependent mating assay described previously (Letourneur et al., 1994). rerl and rer3 mutant cells lacking the chromosomal $\alpha$ factor receptor (Ste2p) were used for this assay. In these ste 2 cells mating requires that some of the plasmid encoded KKXX-tagged Ste2 proteins (Fig. 1A) fail to be retained in the ER. This leakage from the ER leads to plasma membrane exposure of the receptor and thus allows mating of the otherwise sterile host cells.

This assay is very sensitive since very few mislocalized proteins are sufficient for mating. The absence of mating observed with cells lacking the RERl gene indicates that the Rer1 protein is not required for retaining KKXX-tagged proteins in the ER. This is consistent with the observation that the rerl-2 mutant isolated by Nishikawa and Nakano (1993) correctly targets an invertase-Wbp1 hybrid protein (Gaynor et al., 1994).

Different results were obtained for the rer 3 mutants. Two mutant alleles of RER3 had been obtained, rer3-11 and rer327, among which rer3-11 caused a stronger retention defect (Boehm et al., 1994). With the Ste2-Wbp1-based assay efficient mating occurs in rer3-27 mutants and to a much lower extent in rer3-11 cells (Fig. 2A). This indicated a defect in the targeting of KKXX-tagged ER-proteins at least in rer3-27 mutants. These results were confirmed by following the transport of a chimeric protein composed of the invertase protein fused to the TMD and the cytoplasmic tail of Wbp1p (Inv-Wbp1p, Fig. 1B; Gaynor et al., 1994). Here the defect in ER retention results in transport of the Inv-Wbp1 construct to the vacuole and subsequent proteolytic cleavage. Cells producing Inv-Wbp1p were pulsed for 10 minutes and chased for 0 or 1 hour at room temperature. The hybrid protein was recovered by immunoprecipitation with an anti-invertase polyclonal antibody, treated with endoglycosidase $\mathrm{H}$ and resolved on a $8 \%$ polyacrylamide gel. Fig. 2B shows that ER retrieval of Inv-Wbplp is normal in the rer3-11 mutants while the retention defect in rer3-27 is quantitatively similar to that observed in ret $1-1$ mutants.

As with ret1-1 mutants, this lack of retention may be due to a defect in KKXX binding of coatomer from rer3-27 cells. Fig. $2 \mathrm{C}$ shows the results of an in vitro binding assay to a KKXXcarrying matrix with extracts from rer3-27 and rer3-11 cells (Letourneur et al., 1994). While coatomer from an extract of 
Fig. 1. Schematic illustration of the hybrid proteins used in this study. The constructs were used for the experiments shown in the following figures: (A) Fig. 2A; (B) -Fig. 2B; (C) Fig. 3; (D) Fig. 4; (E and F) Fig. 5A,B; (G) Fig. 5C.

(A and B) KKXX-tagged versions of the Ste 2 receptor and invertase, respectively (Letourneur et al., 1994; Gaynor et al., 1994). The $C$ terminus of these hybrid proteins is derived from Wbplp a subunit of the oligosaccharyl transferase of the ER (te Heesen et al., 1993). The two versions of Sec12-invertase (C,D) had been used to select and characterize the rer mutants, while results obtained with the analogous Sec22 and Sec22/12 chimeras (E,F) had shown that the transmembrane domain of Sec $12 p$ mediates Rer1p-dependent ER retention (Boehm et al., 1994). The construction of Sec22- $\alpha$ factor is described in this work. The c-myc epitope present in D and $\mathrm{G}$ is represented by a black box. It precedes the sequence YKREAEA which is cleavable by the late Golgi protease Kex2p. Invertase is encoded by the $S U C 2$ gene. $\alpha$ Factor is a 13 residue long mating pheromone produced by MATacells.
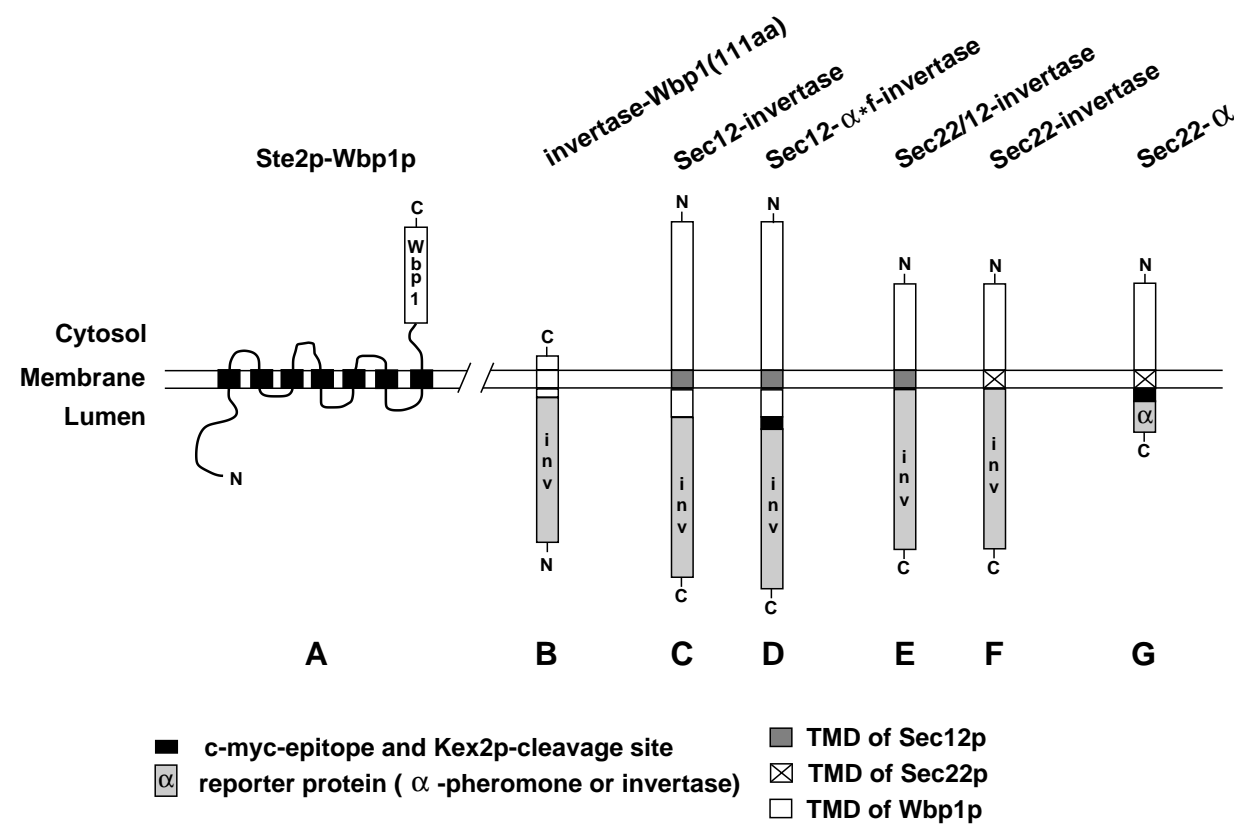

c-myc-epitope and Kex2p-cleavage site $\triangle$ TMD of Sec22p TMD of Wbp1p rer3-11 mutants binds to the KKXX column as efficiently as coatomer from wild-type cells, coatomer from a rer3-27 is not able to bind to this affinity matrix. Thus, in rer3-27 mutants the lack in KKXX retention goes along with a defect in the in vitro binding to the $\mathrm{KKXX}$ affinity matrix very much like in ret $1-1$ and $\sec 27-1$ mutations.

\section{rer3 mutations represent unique alleles of the aCOP encoding RET1 gene}

The lack of Ste2-Wbp1p retention indicated that the rer3 mutations may affect a component of the yeast coatomer or a regulatory element involved in the formation of the yeast coatomer. To reveal possible genetic interactions between rer3 and other coatomer mutations we tried to create double mutants of the rer3 mutations and ret1-1, sec21-2 and sec27-1 mutations, respectively. In the course of these experiments the following evidence for rer3 mutations being novel alleles of the $\alpha C O P$ encoding RET1 gene were obtained: (i) ret1-1 mutants cannot complement the defect in Sec12-invertase retention of rer3 mutants as indicated by the $\mathrm{Suc}^{+}$phenotype of heterozygous ret1-1 rer3 cells expressing the SEC12-ofSUC2 hybrid gene (Boehm at al., 1994). (ii) Only one wildtype spore $\left(\mathrm{Ts}^{+}, \mathrm{Suc}^{-}\right)$was obtained among 153 spores from crosses between ret1-1 with either rer3-27 or rer3-11. Therefore, RET1 and RER3 are at least very closely linked genes. (iii) The RET1 gene expressed from a centromeric vector is able to suppress the Kex2p-dependent invertase secretion of SEC12- $\alpha f-S U C 2$ expressing rer3 mutants as well as the instability of epitope-tagged Sec12 proteins in rer3-11 mutants (data not shown). In addition, the sequence of the RET1 gene from the rer3-11 mutant revealed a specific missense mutation in one of the WD40 repeats of $\alpha C O P$ (F. Letourneur, unpublished results).

The genetic experiments also showed that rer3 sec $21-2$ and rer3 sec $27-1$ double mutants are viable. In this respect, rer3 mutations differ from the ret $1-1$ allele. This lack of genetic interaction may be due to the fact that, unlike the ret $1-1$ allele, none of the rer3 mutations results in temperature-sensitive growth. As with ret $1-1$ mutants, rer3 mutants did not show a defect in the transport of the lysosomal hydrolase CPY (data not shown). Moreover, rer3 mutants do not show a defect in outer chain glycosylation of invertase as do, for instance, rerl mutants (data not shown).

Taken together, these results suggest that RER3 and RETI are allelic. Especially, the rer3-11 seems to represent a RET1 allele with unique properties. Since it interferes with the targeting of Sec12p without affecting the recycling of KKXXtagged proteins, we renamed this allele ret $1-12$.

\section{The ret1-12 mutation increases the rate of Golgi- modification of Sec12-invertase}

Mislocalization of proteins can be analyzed by using their sugar modifications as an indicator of their progress within the secretory pathway (Franzusoff and Schekman, 1989; Gaynor et al., 1994). Pulse-chase experiments were performed to compare the N-linked glycosylation of Sec12-invertase (Fig. 1C). SEC12-SUC2 was expressed in ret1-12 cells, rer1- ${ }^{-}$single mutants and ret $1-12$ rerl-double mutants (Fig. 3A). As shown before, Sec12-invertase is found in its core-glycosylated form in wild-type cells (d'Enfert et al., 1991; Boehm et al., 1994). It receives outer chain glycosylation in a very slow reaction (Fig. 3A, lane 2, lower panel). In contrast, Sec12-invertase expressed in rer $^{-}$mutants is strongly glycosylated resulting in a shift in electrophoretic mobility of the protein (Fig. 3A, lane 6). The slower migrating proteins carry Golgi modifications as shown by precipitation with an d-6 mannosylation specific serum (Boehm et al., 1994; see also Fig. 3A, lane 6 and 8 , lower panel). As in wild-type cells, no significant increase in the size of Sec12-invertase was seen in ret1-12 mutants (Fig. 3A, lane 4). However, reprecipitation with an $\mathbf{d}$ - 
A
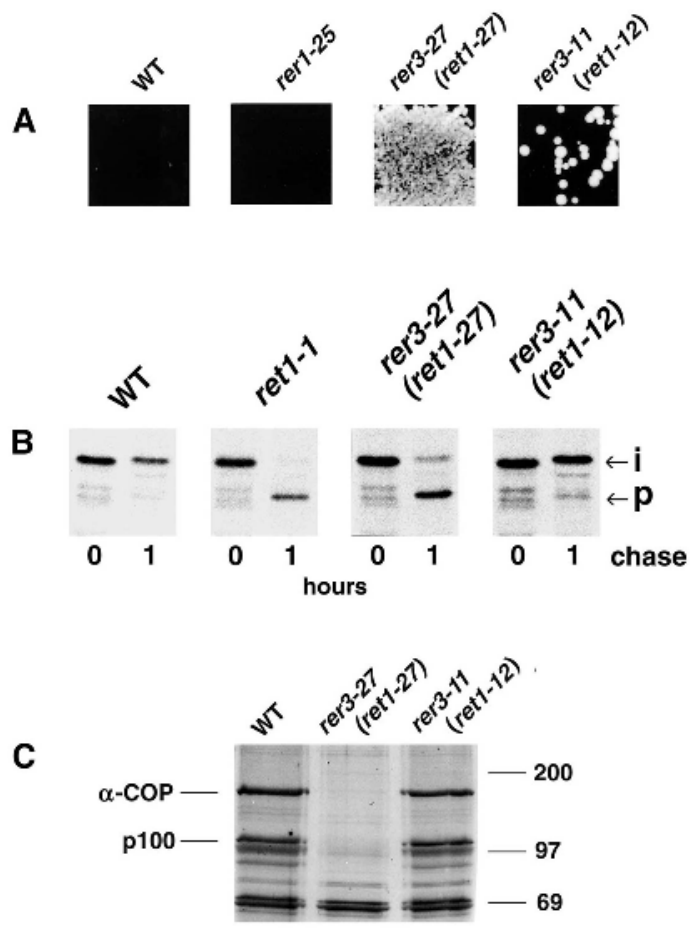

Fig. 2. (A) Mating assay to examine rer mutants for defects in ER retention of KKXX-tagged proteins. MATa, ste 2 cells expressing the STE2-WBP1 chimera (WT: FLY62, rer1-25:FLY37, rer3-27:FLY35, rer3-11:FLY85) carrying the C-terminal KKXX retention signal were grown on YEPD plates replica-plated to a lawn of MATocells (RH311-3D). After 6 hours of mating at $30^{\circ} \mathrm{C}$, cells were replicaplated to SD plates selective for growth of diploid cells. (B) Assay for retention defects of KKXX-carrying invertase-Wbp1 hybrids. Wild-type (JBD2-2A), ret1-1 (EGY101), rer3-27 (C21.27-2D) and rer3-11 (R3P4-10A) cells expressing the Inv-Wbp1 fusion proteins were pulsed for 10 minutes with Tran $\left[{ }^{35} \mathrm{~S}\right]$-label and chased for 0 or 1 hour at room temperature. Inv-Wbplp was immunoprecipitated from the labelled cells with an anti-invertase serum, treated with endo $\mathrm{H}$ and analyzed on an SDS-polyacrylamide gel. Intact (i) and processed (p) hybrid protein migrated at 70 and $56 \mathrm{kDa}$, respectively. (C) In vitro binding assay of coatomer to the dilysine motifs. Whole cell lysates from the indicated cells were incubated with WBP1 peptide coupled to Sepharose beads. The adsorbed proteins were separated by SDS-PAGE and revealed by silver staining. The position of $\alpha \mathrm{COP}$ and the 100 family $(\beta, \beta-$, and $\gamma \mathrm{COP})$ are indicated.

6 mannose-specific serum showed that the protein receives o 6 mannosyl residues to a much higher extent than in wild-type cells (Fig. 3A, lane 4, lower panel). This type of Golgi-specific glycosylation is likely to be due to the initiation of $\alpha-6$ mannosylation which is catalyzed by the Och1 protein in a very early Golgi compartment of yeast (Nakanishi-Shindo et al., 1993; Gaynor et al., 1994). The absence of extensive outer chain elongation suggests that Sec12-invertase produced in a ret1-12 mutant is either trapped in the Och1p-containing Golgi compartment or penetrating a little further into the Golgi compartment than in wild-type cells. (The two types of glycosylation described here are more clearly distinguishable when pulse-chase experiments were carried out with a different hybrid protein in a wild-type background as shown in Fig. 5.)

Sec12-invertase may receive OCH1-specific glycosylation
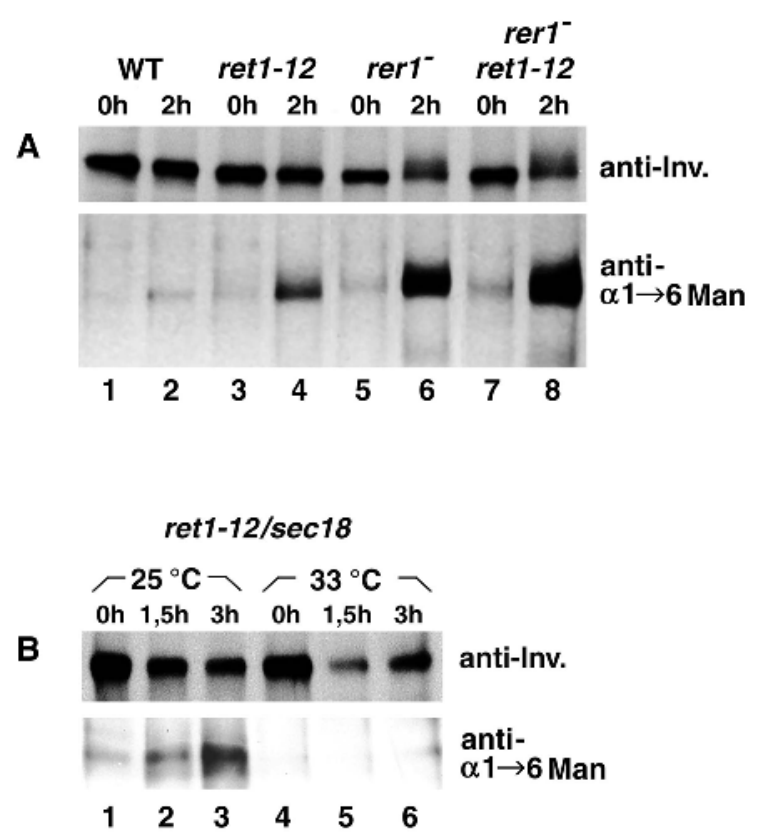

Fig. 3. Outer chain glycosylation of Sec12-invertase hybrids in ret112 and rerl $^{-}$mutants. (A) Pulse-chase experiments were performed using R1R3 strains (Table 1) with genotypes as indicated. Cells were labelled with Tran $\left[{ }^{35} \mathrm{~S}\right]$-label for 15 minutes. Extracts were prepared 0 and 2 hours after the labelling of the cells. Sec12-invertase was precipitated from the extract by using an anti-invertase serum. Precipitated proteins were eluted from Protein A-Sepharose beads and aliquots were resolved by SDS-PAGE. Dried gels were exposed to fluorography. (B) Comparison of $\alpha-6$ mannosylation between wild-type, ret 1-12 $\mathrm{rerl}^{-}$and ret1-12 $\mathrm{rerl}^{-}$cells. Aliquots of samples presented in A were reprecipitated with an anti-d -6 Man serum. (C) Golgi modification of Sec12-invertase in the ret1-12 mutants requires ER-to-Golgi transport. A sec18 retl-12 double mutant was labelled with Tran $\left[{ }^{35} \mathrm{~S}\right]-$ label at $25^{\circ} \mathrm{C}$. The sample was split at the beginning of the chase period. The two samples were incubated either at the permissive temperature of $25^{\circ} \mathrm{C}$ or at $33^{\circ} \mathrm{C}$ to block ER to Golgi transport. Aliquots were taken at the indicated times. Extracts were prepared and treated with anti-invertase serum. After elution from the Protein A-Sepharose beads the samples were spilt and reprecipitated with anti-invertase antibodies again or with anti-d -6 Man serum as indicated.

upon mislocalization to the Golgi compartment. Alternatively, the ret 1-12 mutation may cause premature $\alpha-6$ mannosylation in the ER by allowing newly synthesized enzymes to be active while they are passing through the ER. To exclude this possibility the SEC12-SUC2 hybrid gene was expressed in a sec 18 ret1-12 mutant and the processing of the hybrid protein was followed both at $25^{\circ} \mathrm{C}$ and at $33^{\circ} \mathrm{C}$. At $33^{\circ} \mathrm{C}$ most vesicular protein transport is blocked in sec18 mutants (Novick et al., 1981; Graham and Emr, 1991). Labelling of the cells was performed at the permissive temperature. The sample was split and each half of the cells was incubated at either the permissive or nonpermissive temperature, respectively. Fig. 3B shows that the shift to $33^{\circ} \mathrm{C}$ completely blocked the a -6 mannosylation that was observed at $25^{\circ} \mathrm{C}$. This suggests that Sec12invertase had to leave the ER to receive OCH1-specific glycosylation in ret 1-12 mutants. In addition, experiments presented below show that the Kex2p-dependent invertase secretion in 
retl mutants is not due to mislocalization of the late Golgi protease.

Besides ret 1-12 mutants, none of the other coatomer mutants expressing SEC12-af-SUC2 showed detectable Kex2pdependent invertase secretion. However, mislocalization of Sec12-invertase to the Och1p-containing Golgi compartment may not be confined to ret $1-12$ mutants. When grown at $30^{\circ} \mathrm{C}$ Sec12-invertase from ret $1-1$ and ret3-1 mutants could also be precipitated at levels above wild-type using $\mathrm{d}-6$ Man antibodies. At least in sec27-1 mutants mislocalization of Sec12invertase can be induced by an incubation at temperatures above $30^{\circ} \mathrm{C}$ (data not shown). The amount of hybrid protein that could be reprecipitated with $\mathrm{d}-6$ Man specific serum from a sec 27-1 extract was still lower than in ret1-12 mutants.

\section{The effects of ret1-12 and rer1 are not additive}

rerl mutants cause a stronger Sec12-invertase defect in Sec12invertase retention than ret1-12 mutants (Boehm et al., 1994). Accordingly, using d-6 mannose specific antibodies less Sec12-invertase could be precipitated from extracts of ret1-12 mutants compared to extracts of rerl-mutants (Fig. 3A). We also examined whether the two defects are additive (Fig. 3, lanes 6 and 8). Variable results were observed in different pulse-chase experiments. To avoid errors due to variable efficiencies of labelling and precipitation, Kex2p-dependent invertase secretion was used to reveal subtle differences between rerl $^{-}$single and rerl- ${ }^{-}$ret1-12 double mutants. This assay employed the transient expression of a SEC12-SUC2 hybrid gene encoding a protein in which the Sec12 and invertase parts were separated by a Kex $2 p$ cleavable site (SEC12-@f-invertase; Fig. 1D; Boehm et al., 1994). Kex2p efficiently releases invertase from hybrid proteins passing through a late Golgi compartment (Graham and Emr, 1991; Boehm et al., 1994; Chapman and Munro, 1994). Therefore, Kex2p-dependent invertase secretion can indicate mislocalization of hybrid proteins that are normally retained in early compartments of the secretory pathway. Transient expression of the hybrid protein was achieved by the addition of galactose for 30 minutes to induce a GAL1 promoter controlled SEC12- $\alpha f$ $S U C 2$ construct. To stop expression of the hybrid gene, cells were collected by centrifugation and resuspended in glucosecontaining medium. This pulse gave rise to about 16 units of total invertase activity. At full induction about 80 units of total invertase activity could be reached.

The amount of internal and external invertase activity was determined at different time points before glucose addition to the cells. No significant difference between rer $^{-}$-single mutants and rer $^{-}$ret 1-12 double mutants could be observed (Fig. 4). As a control, the amount of secreted and total invertase was determined when the GAL1-regulated SEC12- $\alpha f-S U C 2$ construct was expressed in wild-type cells and ret 1-12 mutants.

Taken together these results indicate that the mislocalization of Sec12-invertase in a rerl-background cannot be aggravated by the rerl-12 mutation.

\section{Sec22(Sly2)p-based chimeras}

Several assays using Sec22(Sly2) chimeras served as controls for the experiments shown above. Sec22(Sly2)p is a protein with a similar topology to Sec12p. It is a synaptobrevin-like protein (Dascher et al., 1991) and acts as a vesicle-specific receptor, a so-called $v$-SNARE in the targeting of ER-derived

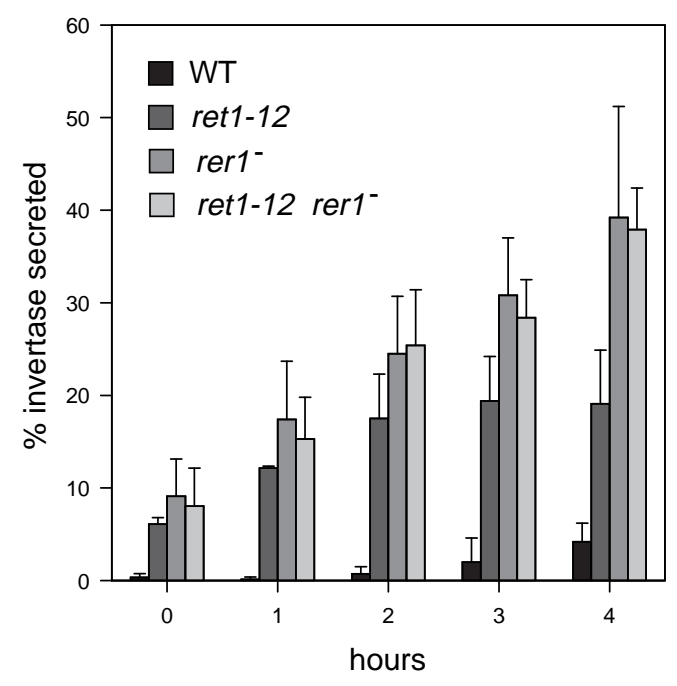

Fig. 4. A 30 minute pulse of hybrid protein expression was achieved by using a GAL1-regulated copy of the SEC12- $\alpha f-S U C 2$ hybrid gene. Samples were taken before and at different times after the incubation with galactose. External and total invertase were measured. The percentage of invertase secreted is indicated. Data represent mean values obtained in at least three different experiments.

vesicles (Søgaard et al., 1994). Sec22p is enriched several hundredfold during the budding of transport vesicles at the ER to the Golgi (Rexach et al., 1994). It is generally believed that Sec22p along with other $v$-SNAREs is retrieved from the Golgi by COPI coated vesicles (Pelham, 1994; Duden et al., 1994). Sec12 protein, in contrast, could not be detected on transport vesicles (Barlowe et al., 1994). Accordingly, the rate of Kex2pdependent invertase secretion is much higher from cells expressing SEC22- $\alpha f-S U C 2$ than from cells expressing SEC12- $\alpha f-S U C 2$. Obviously, the fast exit of Sec22-chimeras from the ER also promotes rapid transport to the late Golgi. Sec22-invertase hybrids can become ER resident proteins if their TMD is replaced by that of Sec $12 p$, and the retention of such a Sec22/12-invertase hybrid depends on Rer1p (Boehm et al., 1994).

One important reason for employing Sec22- and Sec22/12chimeras as a control was the fact that experiments using these chimeras could be carried out in wild-type cells instead of rer 1 mutants. rerl mutants exhibit a defect in outer chain glycosylation of invertase. Therefore, there is only a small difference in the mobility of Sec12-invertase from ret1-12 and rer1mutants (Fig. 3A). The pulse-chase experiment shown in Fig. 5A (lanes 1 to 3 ) demonstrates that Sec22-invertase rapidly receives outer chain glycosylation. This leads to an extensive smear which is characteristic for secreted invertase. Sec22/12invertase behaves differently (see Fig. 1E and F for a comparsion of the two hybrid proteins). Even 90 minutes after the labelling reaction, Sec22/12-invertase migrates as a sharp band with the same size as at the beginning of the chase period. However, reprecipitation with d-6-man specific serum indicated that a large portion of the Sec22/12-invertase protein had reached an early Golgi compartment where the $\alpha-6$ mannosylation is initiated by Och1p. Therefore, Sec22/12-invertase very much resembles Sec12-invertase expressed in a ret1-12 mutant. In the absence of Rer1p Sec12-invertase receives 

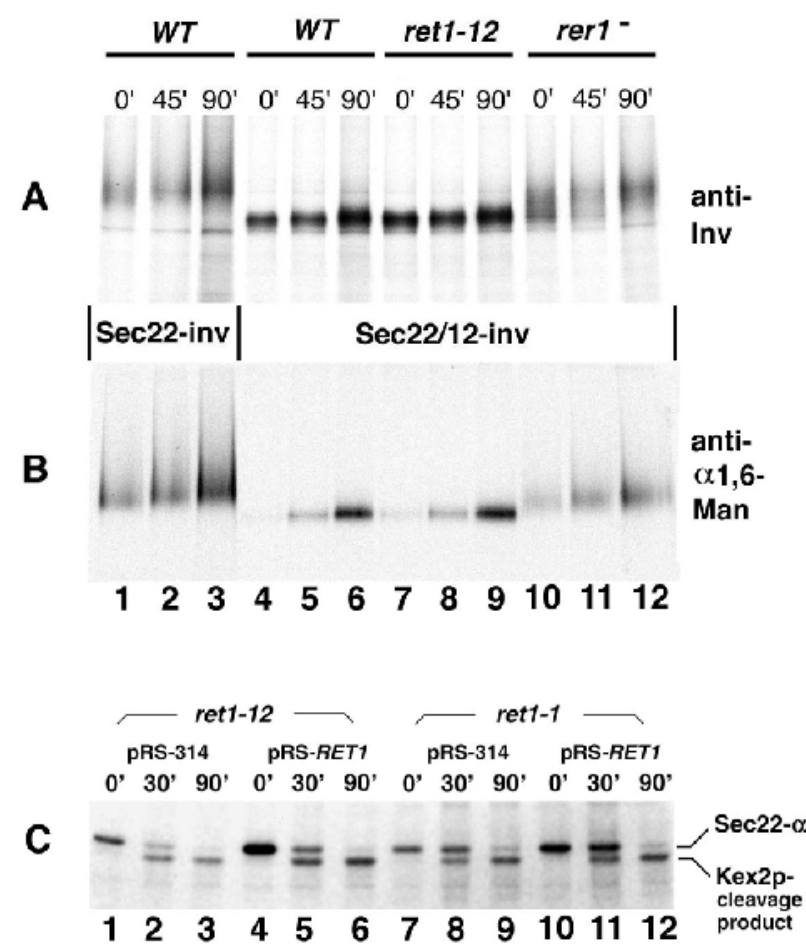

Fig. 5. Pulse-chase experiments using Sec22-derived chimeras. (A) Sec22-invertase and Sec22/12-invertase (lacking a Kex2pcleavage site) were expressed in a protease-deficient \$ep 4 strain (R1R3-7A-pBLYS-ret1, WT; lanes 1 to 6; R1R3-7A, ret1-12; lanes 7 to 6; R1R3-10A-pLys-RET1, ser1). Cells were radiolabelled for 15 minutes at $30^{\circ} \mathrm{C}$ and then chased at the same temperature for 0,45 , and 90 minutes. (B) After the first precipitation using anti-Sec22p antibodies and elution from the Protein A-Sepharose beads, half of the samples were reprecipitated with an anti-ol-6 man serum. (C) Sec22- $\alpha$ factor cleavage by Kex $2 p$ is not increased in ret 1 mutants. To analyze the effect of different RET1 alleles on the transport of Sec22-afactor, pulse-chase experiments were performed using mutants expressing moderate levels of the hybrid gene ( $\mathrm{CYCl}$ promoter, CEN-based vector). To obtain isogenic strains mutants were transformed either with vector pRS314 or pRS314-RET1 carrying the wild-type gene. Labelling and chase were performed in synthetic minimal medium selective for both plasmids. Note that the cleaved hybrid protein still carries segments encoded by polylinker regions in addition to the c-myc-epitope. Therefore, it still migrates above the Sec22 protein derived from the chromosomal wild-type gene which can be seen as a faint band below the cleavage product.

extensive outer chain glycosylation (Fig. 5A,B; lane 9 to 12 ) indicating that Rer1p prevents the exit of chimeras carrying the TMD of Sec12 from an early Golgi compartment.

Fig. 5A and $\mathrm{B}$ also show that the Golgi modification of Sec22/12-invertase is not accelerated by the ret $1-12$ mutation (compare lanes 4 to 6 and 7 to 9). This result was confirmed by assays using the analogous hybrid protein carrying a Kex2cleavage site. Neither by measuring the amount of invertase secreted, nor by immunoblot analysis were we able to find a significant difference between wild-type and ret $1-12$ cells (data not shown).

The much faster transport of Sec22-invertase compared to Sec12-invertase may in part be an artifact caused by the bulky invertase reporter. To test this, a new chimera was constructed, Sec22- $\alpha$ factor (see Fig. 1G). This chimeric protein differs from the previously used hybrids by carrying a short ofactor peptide as a reporter (13 residues; Kurjan and Herskowitz, 1982) instead of invertase $(69 \mathrm{kDa})$. Pulse-chase experiments were performed using wild-type and mutant cells expressing moderate levels of the Sec22-afactor hybrid (CYCl promoter, CEN-based vector). To obtain pairs of truly isogenic strains, ret1-12 mutants were transformed either with the pRS314 vector alone or pRS314 containing the RET1 gene (pRS314-

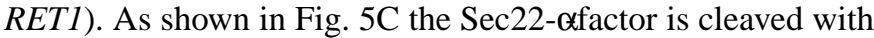
a half-time of about 30 minutes. This cleavage does not occur in Kex2p-deficient cells (not shown). The half time for cleavage by Kex $2 p$ of about 30 minutes is rather slow when compared to a half time of 5 minutes for an analogous hybrid protein derived from the cis-Golgi glycosyltransferase Och1p (Harris and Waters, 1996). Even longer half times can be obtained when less Sec22-afactor is produced (W. Ballensiefen and H. D. Schmitt, unpublished results). Thus, targeting of Sec22p-derived chimeras is sensitive to the reporter to which it is fused as well as to the rate of expression. In these respects Sec22 hybrids differ greatly from analogous Sec12 hybrids.

No significant difference between wild-type and ret $1-12$ and ret 1-1 mutants was observed when the rate of Kex2 processing of Sec22- $\alpha$ factor were compared (Fig. 5C). In these experiments labelling and chase were performed at $30^{\circ} \mathrm{C}$. Under these conditions both mutants exhibit the missorting defect as indicated by using the Sec12-invertase and Ste2-Wbp1p test system.

Obviously, ret1 mutants do not disturb the targeting Sec22p. This, of course, does not rule out the possibility that coatomer is involved in the recycling of Sec22p. The experiment shown in Fig. 5C also indicates that the Kex2p-dependent invertase secretion, the approach by which the 'rer3' mutants had been selected, is not due to an increased activity of Kex2p in an early secretory compartment.

\section{Rer1p localization}

Comparing the mislocalization defects in rerl and retl mutants suggested that $\alpha \mathrm{COP}$ encoded by RETl may act before Rer1p, therefore placing Rerlp into the Golgi. This was confirmed by double labelling immunofluorescence. Formaldehyde-fixed spheroplasts of cells expressing normal levels of Rer1p were incubated with affinity-purified antiRer1p antibodies. A monoclonal antibody directed against the C terminus of Ypt1p was used to visualize this Golgi marker (Haubruck et al., 1987; Preuss et al., 1992). To facilitate double labelling with additional marker proteins, transformants were used that expressed tagged versions of these proteins. Och1p was employed as a marker for an early Golgi compartment (Nakanishi-Shindo et al., 1993; Gaynor et al., 1994), Pmrlp as marker for the medial Golgi (Antebi and Fink, 1992; Schröder et al., 1995) and Kex2p as marker for a late Golgi compartment (Redding et al., 1991). These proteins were either c-myc- or hemagglutinin(HA)-tagged versions carried by multi-copy plasmids (Och1p-myc and HA-Pmr1p; M. Lewis, personal communication; Antebi and Fink, 1992), or expressed from CEN-based single copy plasmids (Kex2pHA; Nothwehr et al., 1995). Staining with each of these antibodies gave a punctuate pattern (Fig. 6). Overlap in the staining pattern between Rerlp and the different Golgi markers was quantitated as described by Antebi and Fink (1992). All antibodies stained about two to three dots per cell. 

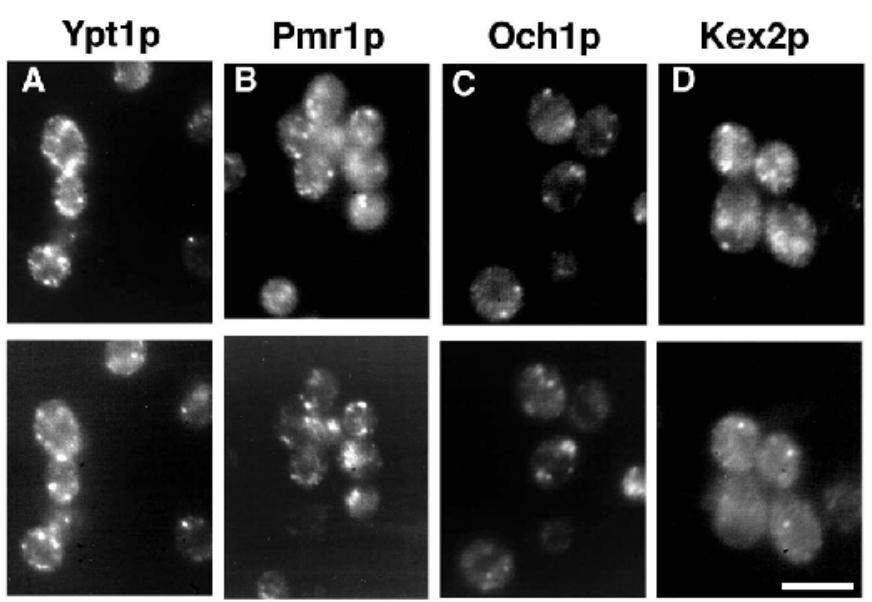

Rer1p

Fig. 6. Double labelling of wild-type cells (JBD2-2A) with antiRer1p antibodies and the Golgi markers Ypt1p, Pmr1, and Och1p. Wild-type cells or transformants carrying plasmids for the expression of epitope-tagged Golgi markers were fixed, permeabilized and treated as described in Materials and Methods. Fixed cells were incubated with monoclonal antibodies (upper panels) directed against either Ypt1p, 9E10 antibody directed against the c-myc-epitope to visualize c-myc-tagged Och1p or 12CA5 antibody directed against the HA epitope to visualize HA-tagged Pmr1p and Kex2p. All samples labelled with an affinity-purified anti-Rer1 antibody (lower panels). Cy3-conjugated anti-mouse IgG and FITC-conjugated antirabbit $\mathrm{IgG}$ were used as secondary antibodies. Bar, $5 \mu \mathrm{m}$.

Those which were labelled with Rer1p antibodies were checked for staining by the second antibody and vice versa. The dots associated with Rer1p colocalized best with Ypt1p and Pmr1p (Table 2) and to a lower extent with Och1p. Colocalization of 70 to $80 \%$ may represent the maximal overlap that can be observed since double staining of Ypt1p with both a polyclonal and a monoclonal antibody did not result in a higher degree of colocalization (data not shown). Very little overlap was found when dots associated with Rer1p and the late Golgi marker Kex2p were compared. This indicated that Rerlp resides in the earlier compartments of yeast Golgi.

Similar punctuate structures were observed when a ret 1-12 mutant was stained for Rerlp and Ypt1p. The number of dots associated with Rer1p remained the same, and also the degree of colocalization did not change significantly (80 and $89 \%$, respectively). These experiments were performed in a 4 ep 4 background as well as in $\mathrm{Pep}^{+}$strains (see also Fig. 8G). The pep4 mutation should prevent degradation of proteins missorted to the vacuole. Since pep4 mutants exhibit no vacuolar sorting defect (Klionsky et al., 1990) it should be

Table 2. Colocalization of Rer1p with other Golgi markers

\begin{tabular}{lccc}
\hline Comparison & \% Colocalization & Comparison & \% Colocalization \\
\hline Rer1p¥pt1p & 73 & Ypt1p Rer1p & 76 \\
Rer1p Pmr1p & 72 & Pmr1p Per1p & 67 \\
Rer1p@ch1p & 59 & Och1p Rer1p & 53 \\
Rer1p Kex2p & 22 & Kex2p Rer1p & 24
\end{tabular}

Values refer to the percentage colocalization with respect to the antigen that is listed first.

$\sec 12-425^{\circ} \mathrm{C}$

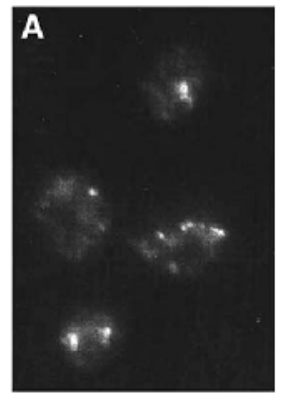

Rer1p
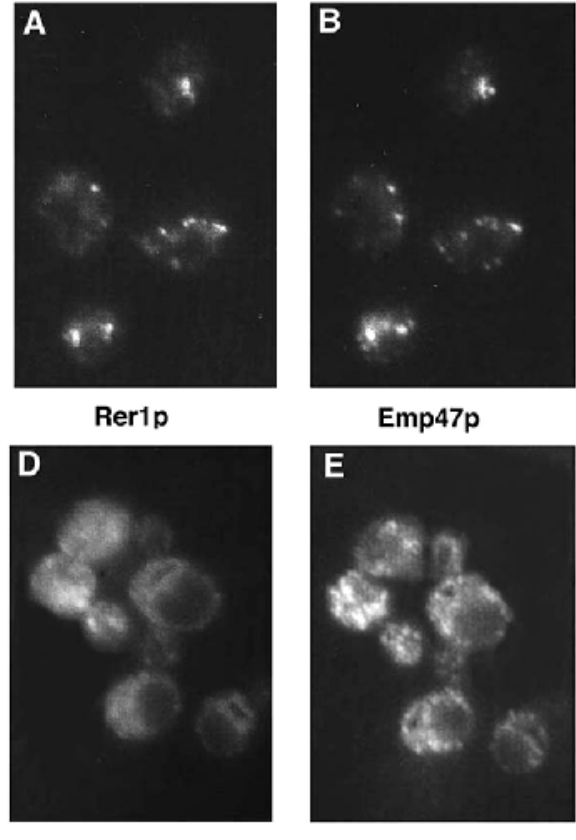

Emp47p

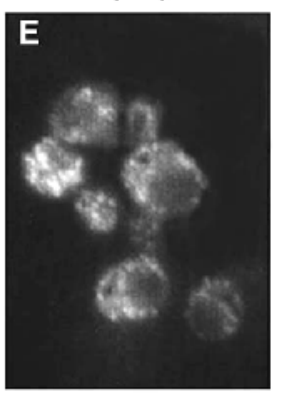

$\sec 12-435^{\circ} \mathrm{C}$

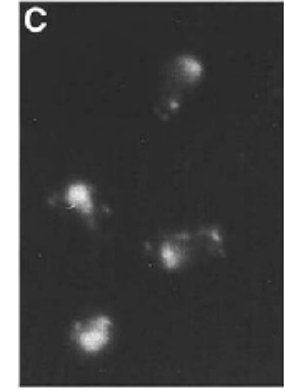

DAPI

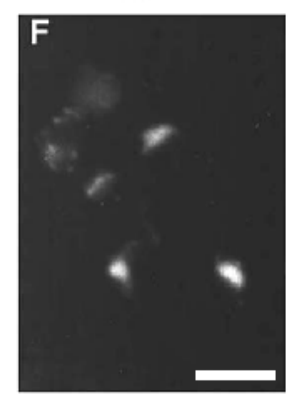

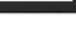

Fig. 7. Immunofluorescence localization to reveal redistribution of Rer $1 \mathrm{p}$ and Emp47p to the ER. A temperature-sensitive sec 12-4 strain (RH3048) expressing c-myc-EMP47 integrated at the LEU2 locus was incubated at $25^{\circ} \mathrm{C}$ (permissive) or $35^{\circ} \mathrm{C}$ (nonpermissive) for 1 hour. $20 \mu \mathrm{g} / \mathrm{ml}$ cycloheximide were added to block protein synthesis. Cells were fixed, permeabilized and stained as described in legend of Fig. 6. In addition to an affinity-purified anti-Rer1p antibody (A and D), the 9E10 monoclonal antibody was used to visualize myc-tagged Emp47 protein. Cy3-conjugated anti-mouse IgG and FITC-

conjugated anti-rabbit IgG were used to stain the antigens. DAPI (1 $\mathrm{MM}$ ) was included in one of the last washing steps to visualize nuclei (C and F). Bar, $5 \mu \mathrm{m}$.

possible to detect missorted proteins that have reached this compartment (Gaynor et al., 1994; Schröder et al., 1995). However, Rer1p antibodies did not stain the vacuole of ret112. Thus, if ret $1-12$ affects $S e c 12 p$ retrieval by first altering the distribution of Rer1p, this must be too subtle a change to be detected by immunofluorescence techniques.

\section{Rer1p recycles to the ER and this recycling is blocked in coatomer mutants}

A high degree of colocalization was also found when the cellular distribution of Rer1p and another Golgi protein, Emp47p, was compared in double immunofluorescence experiments (S. Schröder, personal communication; Fig. 7). Emp47p is a type I transmembrane protein that carries a dilysine motif. It colocalizes best with Pmr1p as determined by cell fractionation and immunofluorescence. Schröder et al. (1995) also demonstrated that Emp47p undergoes retrograde transport from the Golgi to the ER. The assay relies on mutant cells, such as sec12 mutants, that can be blocked in forward transport without disturbing the retrograde transport. As shown by Schröder et al. (1995) for Emp47p and more recently by Lewis and Pelham (1996) for the HDEL-receptor, Golgi proteins 

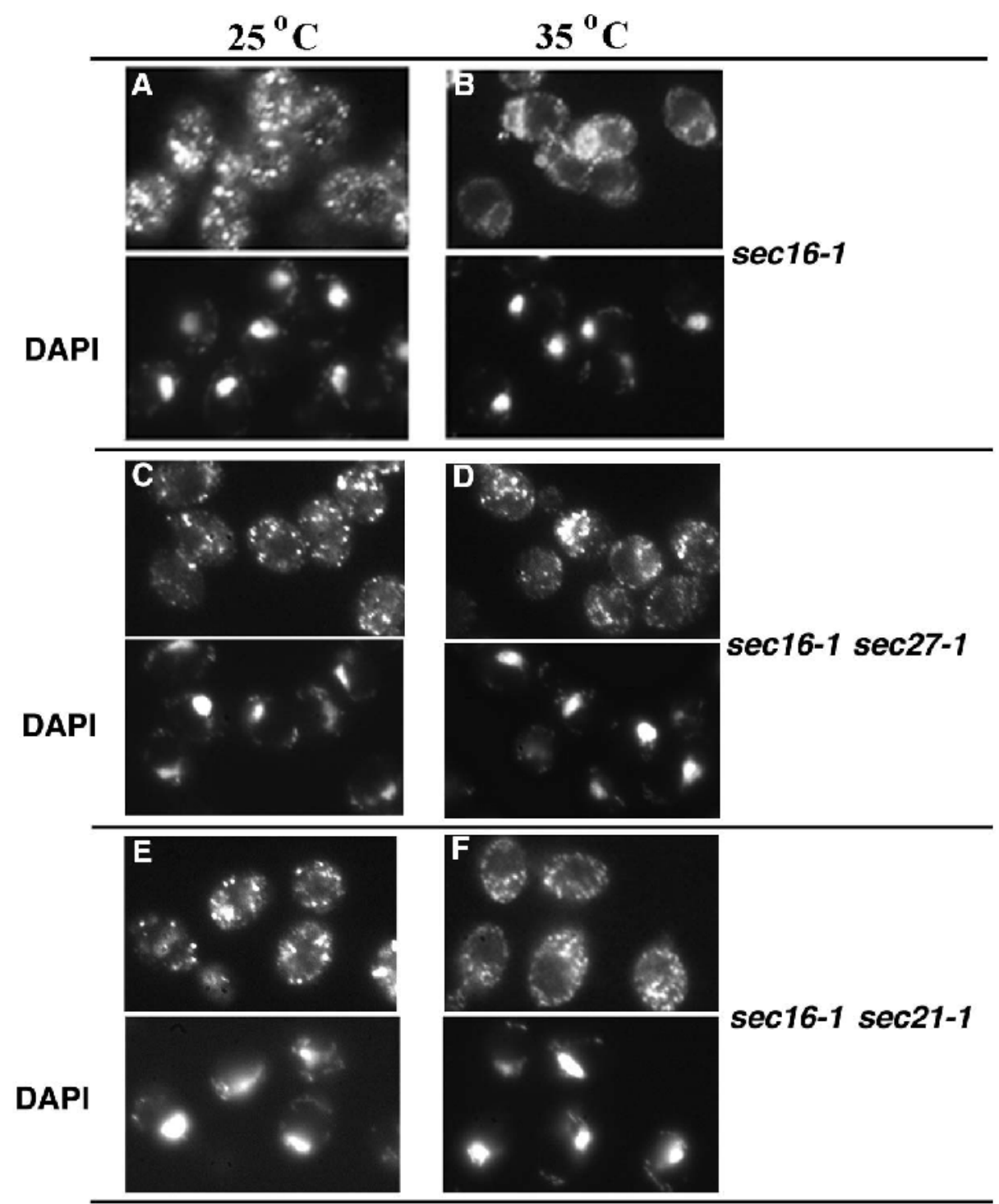

Fig. 8. Immunofluorescence localization of Rer1p in sec16-1 mutants (A and B) and sec16-1 mutants carrying additional COPI defects as indicated. Cells were treated as described in Fig. 7. The cells used were diploid to facilitate the visualization of the different structures. DAPI was used to stain nuclei and mitochondria (panels below the immunofluorescence micrographs).
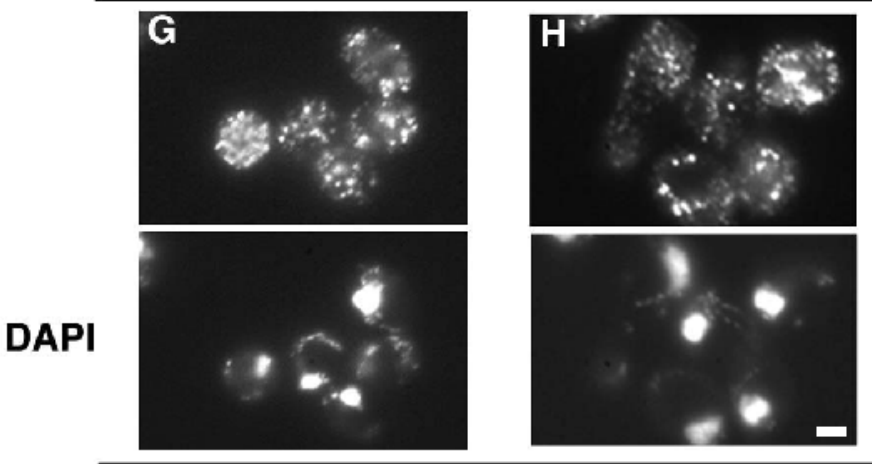

sec16-1 ret1-12 Bar, 5 .m.

which recycle can be trapped in the ER in sec 12 mutants at the nonpermissive temperature. To see whether Rer1p redistributes in a similar way to Emp47p and Erd2p, a sec12-4 mutant expressing a myc-tagged copy of Emp47p from a chromosomally integrated vector was incubated for 1 hour at either $25^{\circ} \mathrm{C}$ or $35^{\circ} \mathrm{C}$. During this incubation further protein synthesis was blocked by the addition of cycloheximide. Cells were fixed and stained for Rer1p and Emp47p. The normal punctuate staining pattern was observed in samples that were incubated at the per- missive temperature $\left(25^{\circ} \mathrm{C}\right.$; Fig. $\left.7 \mathrm{~A}, \mathrm{~B}\right)$. At $35^{\circ} \mathrm{C}$ perinuclear staining typical for the ER of yeast (Rose et al., 1989) was found when cells were stained for Rer1p and Emp47p (Fig. $7 \mathrm{D}, \mathrm{E})$. This result demonstrates that Rer1p recycles between Golgi and ER as shown before for Emp47p and Erd2p.

To investigate whether the recycling of Rer1p is mediated by coatomer (COPI)-coated vesicles, we repeated the redistribution experiment described above using various double mutants. In these mutants a defect blocking the budding of 
COPII vesicles from the ER was combined with mutations in coatomer (COPI)-encoding genes. Diploid cells were used in these experiments to facilitate the visualization of various structures. Staining the cells for Rer1p demonstrated that, unlike sec 12-4 single mutants, sec12-4 ret1-12 double mutants display no ER-like structures when incubated at $35^{\circ} \mathrm{C}$ (data not shown). Additional immunofluorescence experiments were performed using sec16-1 mutants rather than sec12-4 to avoid artifacts due to a possible interaction of Rer1p with mutated Sec12p. The results obtained with sec16-1 confirmed the observations made with sec $12-4$. At $35^{\circ} \mathrm{C}$ the sec $16-1$ single mutants also displayed an ER-like pattern when stained with anti-Rer1p antibodies (Fig. 8B). The ret1-12 mutation inhibits the redistribution of Rer1p to the ER since punctuate structures are still visible in sec16-1 ret1-12 double mutants incubated at $35^{\circ} \mathrm{C}$ (Fig. 8H). Two additonal COPI affecting defects, sec 21 1 and sec27-1, were also combined with the COPII mutation sec16-1 to test the relocalization of Rer1p. Like the ret $1-12$ mutation, the sec 21-1 mutation efficiently prevents the relocalization of Rer1p (Fig. 8F). In sec27-1 sec16-1 mutants some cells still showed a perinuclear ring suggesting that this COPI mutation prevents the recycling of Rerlp to a lower extent (Fig. 8D). Since sec27-1 mislocalizes Sec12-invertase only at higher temperatures and less efficiently than ret $1-12$, these results indicate that the mislocalization of the Sec12p-derived hybrid protein relates to the slowdown of Rer1 recycling. In summary, Rer1p recycles to the ER via coatomer-coated vesicles as described for Emp47p and Erd2p.

\section{DISCUSSION}

ret 1 mutants were first identified as defective in the retention of dilysine-tagged membrane proteins in the ER of yeast. In this work we show that mutations in the $\alpha C O P$-encoding RETI gene also result in mislocalization of membrane proteins different from the dilysine-tagged type I transmembrane proteins. The targeting defects caused by the ret $1-12$ mutant (previously referred to as rer3-11) can occur with only little effect on the retention of KKXX-tagged proteins. The finding that rer3 mutants are alleles of the aCOP encoding RET1 gene suggests that, in addition to the previously characterized Rer1 protein, coatomer contributes to the retention of Sec12p in the ER.

There is certainly a third mechanism that contributes to the targeting of Sec12p. As mentioned before, Sec22p is a protein with a topology similar to that of Sec12p. Unlike Sec12p, however, Sec22p is actively packaged into transport vesicles that bud from the ER (Rexach et al., 1994; Barlowe et al., 1994). Factors that favour active packaging (Sec22p) or delay the exit from the ER (Sec12p) very likely reside in the cytoplasm domain (Sato et al., 1996). The importance of the cytoplasmic domains is also illustrated by the finding that the swapping of the TMDs cannot change Sec12-invertase into a rapidly transported protein like Sec22-invertase, while Sec22/12-invertase is not as efficiently retained in the ER as Sec12-invertase (Boehm et al., 1994; J. Boehm and H. D. Schmitt, unpublished results). As shown here (Fig. 5A), the TMD of the respective hybrid proteins is responsible for determining the rate of exit from a very early Golgi compartment rather than preventing the exit from the ER.

\section{Comparing the ret1 and rer1 defects}

The ret $1-12$ mutation and the rerl defects which were characterized previously (Nishikawa and Nakano, 1993; Boehm et al., 1994) have several features in common. Both defects lead to mislocalization of Sec12-invertase chimeras and to a reduced steady state level of Sec12p or epitope-tagged Sec12 proteins (Boehm et al., 1994; our unpublished results). This instability may be explained by the transport of the mislocated chimeras to the vacuole. Lack of ER retention was demonstrated in two ways: (i) Sec12-invertase carrying an intervening cleavage site for the late Golgi protease Kex2p is cleaved and invertase is released. (ii) The rate of outer chain glycosylation of Sec12invertase is increased in the mutants. In ret1-12 mutants Sec12invertase receives outer chain glycosylation as shown by precipitation with glycosylation specific antibodies. However, this modification did not change the apparent size of the proteins, indicating that the chimeras had reached the earliest Golgi compartment of yeast where $\mathrm{d}-6$ mannosylation is initiated by the Och1 protein (Nakanishi-Shindo et al., 1993; Gaynor et al., 1994; Lehle et al., 1995). In rerl mutants a large part of Sec12invertase receives extensive outer chain glycosylation, a reaction which requires the elongation of the $\alpha-6$ mannose chain in later compartments of the Golgi. Different controls showed that cleavage by Kex $2 p$ was not due to premature activity of Kex $2 p$ in the ER and that the outer chain glycosylation of Sec12p and Sec12-invertase required ongoing ERto-Golgi transport (Nishikawa and Nakano, 1993; this work).

From these phenotypes one could conclude that $\alpha \mathrm{COP}$ and Rer1p both act on the same transport intermediates, Sec12invertase glycosylated by Och1p. While Rer1p may block the transport of this intermediate to later Golgi compartments, $\alpha$ $\mathrm{COP}$ is involved in the recycling to the ER. It should be pointed out that the glycosylation intermediate observed in ret 1 mutants also occurs in wild-type cells, but to a much lesser extent. This suggests that in wild-type cells recycling mediated by COPI vesicles is efficient enough to prevent almost completely the glycosylation of Sec12-invertase by Och1p.

Assuming that Rer1p acts together with or downstream of $\alpha$ COP one would suggest that Rer1p functions in the Golgi. Accordingly, Rer1p was located in the Golgi by fractionation studies as well as by immunofluorescence. There is some overlap between Rer1p and the early Golgi marker Och1p. A higher degree of colocalization was found between Rer1p and the medial Golgi markers Pmr1p and Emp47p. There was only very little overlap in the staining pattern of Rer1p and the late Golgi marker Kex2p. These results are consistent with the findings of Sato et al. (1995) who were able to partially separate HA-tagged Rer1p and Och1p from the late Golgi marker Kex $2 \mathrm{p}$ by a sucrose step gradient, and who found a good colocalization of Ypt1p and HA-tagged Rer1p expressed from a multi-copy vector. Therefore, rather than being part of a rigid retention system that prevents $S e c 12 p$ from exiting the $\mathrm{ER}$, Rer1p carries out its retention function in the early and medial Golgi compartments of yeast.

The following observations are also consistent with the interpretation that Rer1p acts in the Golgi of yeast: a partial defect in outer chain glycosylation of invertase was observed with rerl mutants (Boehm et al., 1994; see also Fig. 5), and a close homolog of RERI was recently isolated from a human cell line. A tagged version of hRer1 localizes to the Golgi and 
Rer1p as adapter

Fig. 9. Two models illustrating the possible role of Rer1p in the recycling of Sec12p. Both transmembrane proteins cycle between ER and Golgi. Rerlp is a transmembrane protein with four transmembrane domains and only a few residues exposed at the luminal side of the membrane compartment (shown as a 'W'). It is necessary for the retrieval of Sec12p or type II transmembrane proteins carrying the TMD of Sec12p. In the first model, Sec $12 p$ binds to Rer $1 p$ directly and serves as an adapter by contacting Sec12p and COPI simultaneously. As shown in the second model, Rer1p may direct Sec12p to certain sites within the Golgi where COPI vesicles can form. In this case, the recycling of Rer1p would be a way to keep Rer1p at its normal locations in the cell. Sec12p and Rer1p may exit their regular sites at low rates to achieve different steady state concentrations in ER and Golgi.
Rer1p recruiting Sec12p to COPI vesicles
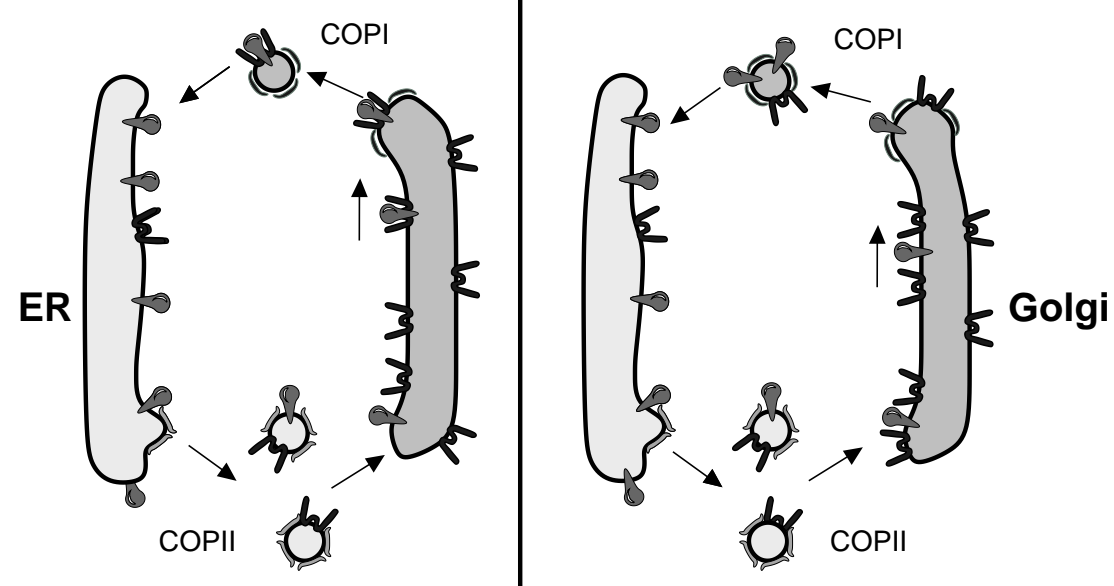

Sec12p W Rer1p ( COPI I COPII

overexpression of this protein leads to relocalization to ER-like structures (J. Füllekrug, J. Boehm, T. Nilsson, G. Mieskes and H. D. Schmitt, unpublished results).

\section{The relationship between aCOP and Rer1p}

In both mutants, retl and rerl, the mislocalization is a rather slow process which takes hours to become evident. Therefore, it was quite surprising that the two defects are not synergistic and not even additive. When discussing the possible functional relationship between $\alpha C O P$ and Rer1p one has to consider this lack of genetic interaction. At least this makes it unlikely that the rerl and ret 1 defects disturb two parallel pathways.

Two models can be envisaged that account for the absence of additive effects (Fig. 9). First, coatomer and Rer1p may cooperate directly in the retention of Sec12p. There is no evidence that COPI interacts with Sec12p. Coatomer may control Sec12p localization through a third protein, possibly Rerlp. The primary defect in the ret $1-12$ mutants may lie in the failure of coatomer to bind the complex of Rer1p and Sec12p and to retrieve this complex to the ER. If Rer1p is absent then, of course, the mislocalization of Sec12p cannot be aggravated by a retl defect.

In this model, Rer1p would act as a receptor or adapter analogous to the HDEL receptor, Erd2p (Semenza et al., 1990; Lewis et al., 1990) or as a cargo receptor like Emp24p (Schimmöller et al., 1995). Similar to the HDEL sequence that binds to the Erd2 receptor, the TMD of Sec12p may represent a domain that is recognized by Rer1p. As with Erd2p, Rer1p would then carry Sec12p to the ER while it is recycling via COPI vesicles. Lewis and Pelham (1996) demonstrated that the recycling of Erd2p receptor requires functional $\gamma \mathrm{COP}$ (Sec21p). Accordingly, we also found that Rer1p recycles to the ER in a COPI-dependent fashion. Emp24p, however, is a constituent of COPII vesicles which is involved in the packaging of specific cargo molecules (Schimmöller et al., 1995). Therefore, it was supposed that its primary function lies in the anterograde transport. Surprisingly, Fiedler et al. (1996) could show that Emp24p binds to coatomer although it is lacking a classical retrieval signal. They also showed that coatomer has more than one binding specificity. This makes it likely that Rerlp which also is lacking any of the known binding motifs for coatomer could be recognized by this coat complex.

In a second model Rer1p may function as sorting factor which is required for the packaging of Sec12p into COPI vesicles. There is no evidence that $\operatorname{Sec} 12 \mathrm{p}$ and Rer $1 \mathrm{p}$ recycle to the ER as a complex. A sorting factor which does not enter vesicles was recently described by Kuehn et al. (1996). Shr3p is required for the packaging of amino acid permeases into COPII vesicles. In contrast to the cargo receptor Emp24p, $\mathrm{Shr} 3 \mathrm{p}$ is not found in COPII vesicles which were obtained in an in vitro reaction. Accordingly, the recycling of Rer1p to the ER would be a way to keep its specific cellular localization. Mislocalization of Sec12p in retl mutants would in that case be the result of an improper targeting of Rer1p caused by a coatomer defect. Coatomer can in fact be involved in the targeting and possibly the functioning of Golgi proteins. Schröder et al. (1995) showed that the Golgi-localization of Emp47p depends on a C-terminal dilysine motif. So far, however, we were unable to observe differences in the localization of Rer1p when comparing wild-type and ret $1-12$ cells. Thus, the defect in ret 1-12 may be due to very subtle differences in the localization or function of Rer1p.

The following observation may disprove these two models. The ret1-12 mutation has no effect on the targeting of Sec22invertase chimeras carrying the TMD of Sec12p (Sec22/12invertase). Retention of this hybrid protein requires Rer1p (Boehm et al., 1994; Sato et al., 1996). If ret1-12 affects Sec12p targeting through Rer1p, then it should also interfere with the targeting of these proteins. This was not the case. The mechanisms preventing Och1p-dependent glycosylation of Sec12-invertase in wild-type cells may be saturable as shown by experiments using strong expression of SEC12-SUC2 from the GAL1 promoter (unpublished results). Since the Sec22p leaves the ER much faster than Sec12p (Rexach et al., 1994; Barlowe et al., 1994), the observation that Sec22/12-invertase is unaffected by the ret 1-12 mutation may be due to saturation of the early Golgi-to-ER recycling process. The more efficient 
retention within the early Golgi may reflect a higher concentration of Rer1p in the medial Golgi compartment as indicated by its colocalization with Emp47p and Pmr1p, whose steady state localization is between the Och1p and the Kex2p subcompartments (Schröder et al., 1995).

From the results presented here it is clear that both coatomer and Rer1p are involved in the retrieval of Sec12p. The results add to the growing list of evidence that COPI vesicles are the common route for the recycling of all type proteins from the Golgi to the ER. Further experiments will be required to see whether Rer1p is itself a part of the recycling machinery or whether it has only a sorting function and recycling is just a way to target this protein correctly. In particular, comparisons between different COPI defects are necessary to confirm a close relationship between the recycling of Sec12p and Rer1p as indicated by the comparison of ret 1-12 and sec27-1 mutants.

We thank Mustafa Benli, Stephan Schröder, Rainer Duden, Michael J. Lewis, Gerry Waters and Dieter Gallwitz for supplying plasmids, strains and antibodies. Special thanks go to Stephan Schröder for helpful discussions and advice with the immunofluorescence. We thank Hans-Peter Geithe for synthesizing oligonucleotides and sequencing and Hannegret Frahm for technical assistance. We are grateful to Peter Ferrari and Helle D. Ulrich for critically reading the manuscript. We thank all members of the Dieter Gallwitz lab for support and encouragement. This work was supported by the Deutsche Forschungsgemeinschaft.

\section{REFERENCES}

Antebi, A. and Fink, G. R. (1992). The yeast $\mathrm{Ca}^{2+}$-ATPase homolog, $P M R 1$, is required for normal Golgi function and localizes in a novel Golgi-like distribution. Mol. Biol. Cell 3, 633-654.

Barlowe, C., Orci, L., Yeung, T., Hosobuchi, M., Hamamoto, S., Salama, N., Rexach, M. F., Ravazzola, M., Amherdt, M. and Schekman, R. (1994). COPII - a membrane coat formed by Sec proteins that drive vesicle budding from the endoplasmic reticulum. Cell 77, 895-907.

Bednarek, S. Y., Ravazzola, M., Hosobuchi, M., Amherdt, M., Perrelet, A., Schekman, R. and Orci, L. (1995). COPI-coated and COPII-coated vesicles bud directly from the endoplasmic reticulum in yeast. Cell 83, 1183-1196.

Boehm, J., Ulrich, H. D., Ossig, R. and Schmitt, H. D. (1994). Kex2dependent invertase secretion as a tool to study the targeting of transmembrane proteins which are involved in ER Golgi transport in yeast. EMBO J. 13, 3696-3710.

Chapman, R. E. and Munro, S. (1994). The functioning of the yeast Golgi apparatus requires an ER protein encoded by $A N P 1$, a member of a new family of genes affecting the secretory pathway. EMBO J. 13, 4896-4907.

Cosson, P. and Letourneur, F. (1994). Coatomer interaction with di-lysine endoplasmic reticulum retention motifs. Science 263, 1629-1631.

Cosson, P., Démollière, C., Hennecke, S., Duden, R. and Letourneur, F. (1996). §COP and $\zeta_{-}$COP, two coatomer subunits homologous to clathrinassociated proteins, are involved in ER retrieval. EMBO J. 15, 1792-1798.

Cosson, P., Schröder-Köhne, S., Sweet, D., Démollière, C., Hennecke, S., Frigerio, G. and Letourneur, F. (1997). The Sec20/Tip20p complex is involved in ER retrieval of dilysine-tagged proteins. Eur. J. Cell Biol. (in press).

d'Enfert, C., Barlowe, C., Nishikawa, S., Nakano, A. and Schekman, R. (1991). Structural and functional dissection of a membrane glycoprotein required for vesicle budding from the endoplasmic reticulum. Mol. Cell. Biol. 11, 5727-5734.

Dascher, C., Ossig, R., Gallwitz, D. and Schmitt, H. D. (1991). Identification and structure of four yeast genes $(S L Y)$ that are able to suppress the functional loss of YPT1, a member of the ras-superfamily. Mol. Cell. Biol. 11, 872-885.

Duden, R., Hosobuchi, M., Hamamoto, S., Winey, M., Byers, B. and Schekman, R. (1994). Yeast $\beta$ and $\beta$-coat proteins (COP). Two coatomer subunits essential for endoplasmic reticulum-to-Golgi protein traffic. J. Biol. Chem. 269, 24486-24495.

Espenshade, P., Gimeno, R. E., Holzmacher, E., Teung, P. and Kaiser, C. A.
(1995). Yeast SEC16 gene encodes a multidomain vesicle protein that interacts with Sec23p. J. Cell Biol. 131, 311-324.

Fiedler, K., Veit, M., Stamnes, M. A. and Rothman, J. E. (1996). Bimodal interaction of coatomer with the p24 family of putative caro receptors. Science 273, 1396-1399.

Franzusoff, A. and Schekman, R. (1989). Functional compartments of the yeast Golgi apparatus are defined by the $\sec 7$ mutation. EMBO J. 8, 26952702.

Gaynor, E. C., Heesen, S. T., Graham, T. R., Aebi, M. and Emr, S. D. (1994). Signal-mediated retrieval of a membrane-protein from the Golgi to the ER in yeast. J. Cell Biol. 127, 653-665.

Graham, T. R. and Emr, S. D. (1991). Compartmental organization of Golgispecific protein modification and vacuolar protein sorting events defined in a yeast sec18 (NSF) mutant. J. Cell Biol. 114, 207-218.

Hardwick, K. G., Lewis, M. J., Semenza, J., Dean, N. and Pelham, H. R. B. (1990). ERD1, a yeast gene required for the retention of luminal endoplasmic reticulum proteins, affects glycoprotein processing in the Golgi apparatus. EMBO J. 9, 623-630.

Harris, S. L. and Waters, M. G. (1996). Localization of a yeast early Golgi mannosyltransferase, Och1p, involves retrograde transport. J. Cell Biol. 132 985-998.

Haubruck, H., Disela, C., Wagner, P. and Gallwitz, D. (1987). The rasrelated ypt protein is an ubiquitous eukaryotic protein: isolation and sequence analysis of mouse cDNA clones highly homologous to the yeast $Y P T 1$ gene. EMBO J. 6, 4049-4053.

Helenius, A. (1994). How N-linked oligosaccharides affect glycoprotein folding in the endoplasmic reticulum. Mol. Biol. Cell 5, 253-265.

Hirschberg, C. B. and Snider, M. D. (1987). Topography of glycosylation in the rough endoplasmic reticulum and Golgi apparatus. Annu. Rev. Biochem. 56, 63-87.

Jackson, M. R., Nilsson, T. and Peterson, P. A. (1990). Identification of a consensus motif for retention of transmembrane proteins in the endoplasmic reticulum. EMBO J. 9, 3153-3162.

Jackson, M. R., Nilsson, T. and Peterson, P. A. (1993). Retrieval of transmembrane proteins to the endoplasmic reticulum. J. Cell Biol. 121, 317333.

Klionsky, D. J., Herman, P. K. and Emr, S. D. (1990). The fungal vacuole: composition, function, and biogenesis. Microbiol. Rev. 54, 266-292.

Kuehn, M. J., Schekman, R. and Ljungdahl, P. O. (1996). Amino acid permeases require COPII components and the ER resident membrane protein Shr3p for packaging into transport vesicles in vitro. J. Cell Biol. 135, 585595.

Kurjan, J. and Herskowitz, I. (1982). Structure of a yeast pheromone gene (MFo): a putative $\alpha$ factor precursor contains four tandem copies of mature $\alpha$ factor. Cell 30, 933-943.

Lehle, L., Eiden, A., Lehnert, K., Haselbeck, A. and Kopetzki, E. (1995). Glycoprotein biosynthesis in Saccharomyces cerevisiae: ngd29, an Nglycosylation mutant allelic to ochl having a defect in the initiation of outer chain formation. FEBS Lett. 370, 41-45.

Letourneur, F., Gaynor, E. C., Hennecke, S., Démollière, C., Duden, R., Emr, S. D., Riezman, H. and Cosson, P. (1994). Coatomer is essential for retrieval of dilysine-tagged proteins to the endoplasmic reticulum. Cell 79, 1199-1207.

Lewis, M. J. and Pelham, H. R. B. (1990). A human homologue of the yeast HDEL receptor. Nature 348, 162-163.

Lewis, M. J., Sweet, D. J. and Pelham, H. R. (1992). The ERD2 gene determines the specificity of the luminal ER protein retention system. Cell 61, 1359-1363.

Lewis, M. J. and Pelham, H. R. B. (1996). SNARE-mediated retrograde traffic from the Golgi-complex to the endoplasmic reticulum. Cell 85, 205-215.

Nakanishi-Shindo, Y., Nakayama, K. I., Tanaka, A., Toda, Y. and Jigami, Y. (1993). Structure of the N-linked oligosaccharides that show the complete loss of $\alpha 1$,6-polymannose outer chain from ochl, och $1 \mathrm{mnn} 1$, and och $1 \mathrm{mnn} 1$ alg3 mutants of Saccharomyces cerevisiae. J. Biol. Chem. 268, 26338-26345.

Nilsson, T., Jackson, M. and Peterson, P. A. (1989). Short cytoplasmic sequences serve as retention signals for transmembrane proteins in the endoplasmatic reticulum. Cell 58, 707-718.

Nishikawa, S.-I. and Nakano, A. (1993). Identification of a novel gene required for membrane protein retention in the early secretory pathway. Proc. Nat. Acad. Sci. USA 90, 8179-8183

Nothwehr, S. F., Conibear, E. and Stevens, T. H. (1995). Golgi and vacuolar membrane-proteins reach the vacuole in vps 1 mutant yeast-cells via the plasma-membrane. J. Cell Biol. 129, 35-46. 
Novick, P., Ferro, S. and Schekman, R. (1981). Order of events in the yeast secretory pathway. Cell 25, 461-469.

Ossig, R., Dascher, C., Trepte, H. H., Schmitt, H. D. and Gallwitz, D. (1991). The yeast $S L Y$ gene-products, suppressors of defects in the essential GTPbinding Ypt1 protein, may act in endoplasmic reticulum-to-Golgi transport. Mol. Cell. Biol. 11, 2980-2993.

Palade, G. (1975). Intracellular aspects of the process of protein secretion Science 189, 347-358.

Pelham, H. R. B. (1988). Evidence that luminal ER proteins are sorted from secreted proteins in a post-ER compartment. EMBO J. 7, 913-918.

Pelham, H. R. B. (1994). About turn for the COPs. Cell 79, 1125-1127.

Pelham, H. R. B., Hardwick, K. G. and Lewis, M. J. (1988). Sorting of soluble ER proteins in yeast. EMBO J. 7, 1757-1762.

Pepperkok, R., Scheel, J., Horstmann, H., Hauri, H. P., Griffiths, G. and Kreis, T. E. (1993). $\beta$ COP is essential for biosynthetic membrane-transport from the endoplasmic reticulum to the Golgi-complex in-vivo. Cell 74, 7182.

Preuss, D., Mulholland, J., Franzusoff, A., Segev, N. and Botstein, D. (1992). Characterization of the Saccharomyces Golgi complex through the cell-cycle by immunoelectron microscopy. Mol. Biol. Cell 3, 789-803.

Redding, K., Holcomb, C. and Fuller, R. S. (1991). Immunolocalization of Kex2 protease identifies a putative late Golgi compartment in the yeast Saccharomyces cerevisiae. J. Cell Biol. 113, 527-538.

Rexach, M. F., Latterich, M. and Schekman, R. W. (1994). Characteristics of endoplasmic reticulum-derived transport vesicles. J. Cell Biol. 126, 11331148

Rose, M. D., Mirsa, L. M. and Vogel, J. P. (1989). KAR2, a karyogamy gene, is the yeast homolog of the mammalian BiP/GRP78 gene. Cell 57, 12111221.

Rothman, J. E. and Orci, L. (1992). Molecular dissection of the secretory pathway. Nature 355, 409-415.

Sato, K., Nishikawa, S. and Nakano, A. (1995). Membrane-protein retrieval from the Golgi-apparatus to the endoplasmic-reticulum (ER) characterization of the RERl gene-product as a component involved in ER localization of Sec12p. Mol. Biol. Cell 6, 1459-1477.
Sato, M., Sato, K. and Nakano, A. (1996). Endoplasmic reticulum localization of Sec12p is achieved by two mechanisms: Rer1p-dependent retrieval that requires the transmembrane domain and Rerlp-independent retention that involves the cytoplasmic domain. J. Cell Biol. 134, 279-293.

Schimmöller, F., Singer-Krüger, B., Schröder, S., Krüger, U., Barlowe, C. and Riezman, H. (1995). The absence of Emp24p, a component of ERderived COPII-coated vesicles, causes a defect in transport of selected proteins to the Golgi. EMBO J. 14, 1329-1339.

Sherman, F., Fink, G. R. and Hicks, J. B. (1986). Methods in Yeast Genetics. Cold Spring Harbour Laboratory Press, Cold Spring Harbour, NY.

Schröder, S., Schimmöller, F., Singer-Krüger, B. and Riezman, H. (1995) The Golgi-localization of yeast Emp47p depends on its di-lysine motif but is not affected by the ret1-1 mutation in $\alpha$ COP. J. Cell Biol. 131, 895-912.

Schutze, M. P., Peterson, P. A. and Jackson, M. R. (1994). An N-terminal double-arginine motif maintains type-II membrane-proteins in the endoplasmic reticulum. EMBO J. 13, 1696-1705.

Semenza, J. C., Hardwick, K. G., Dean, N. and Pelham, H. R. B. (1990). $E R D 2$, a yeast gene required for the receptor-mediated retrieval of luminal ER proteins from the secretory pathway. Cell 61, 1349-1357.

Sikorski, R. S. and Hieter, P. (1989). A system of shuttle vectors and yeast host strains designed for efficient manipulation of DNA in Saccharomyces cerevisiae. Genetics 122, 19-27.

Søgaard, M., Tani, K., Ye, R. R., Geromanos, S., Tempst, P., Kirchhausen, T., Rothman, J. E. and Söllner, T. (1994). A rab protein is required for the assembly of snare complexes in the docking of transport vesicles. Cell 78, 937-948.

te Heesen, S., Knauer, R., Lehle, L. and Aebi, M. (1993). Yeast Wbp1p and Swp1p form a protein complex essential for oligosaccharyl transferase activity. ЕMBO J. 12, 279-284.

Townsley, F. M. and Pelham, H. R. B. (1994). The KKXX signal mediates retrieval of membrane-proteins from the Golgi to the ER in yeast. Eur. J. Cell Biol. 64, 211-216.

(Received 17 December 1996 - Accepted 18 February 1997) 